\title{
ANALISIS KEMAMPUAN MPEG SPATIAL AUDIO OBJECT CODING UNTUK REPRODUKSI AUDIO MULTIKANAL
}

\author{
Amirul Luthfi dan Ikhwana Elfitri* \\ Jurusan Teknik Elektro, Fakultas Teknik, Universitas Andalas \\ *Corresponding author, e-mail: ikhwana@ ft.unand.ac.id
}

\begin{abstract}
Abstrak- MPEG Spatial Audio Object Coding (MPEG SAOC) merupakan pengkode audio berbasis objek pertama yang telah telah distandarisasi oleh International Organization for Standardization (ISO). MPEG SAOC memiliki kemampuan reproduksi audio multikanal pada sisi decoder. Pada paper ini, dianalisis kemampuan reproduksi audio multikanal pada decoder MPEG SAOC dan dibandingkan dengan MPEG Surround (MPS). Hasil penelitian menunjukkan, MPEG SAOC dan MPS sama-sama memiliki Objective Difference Grade (ODG) pada level imperceptible. Namun, encoder MPEG SAOC hanya mendukung masukan satu objek audio multikanal saja.
\end{abstract}

Kata Kunci : Spatial Audio Object Coding, Audio berbasis Objek dan Audio Multikanal

\begin{abstract}
MPEG Spatial Audio Object Coding (MPEG SAOC) is the first standard on object-based audio coding released by International Organization for Standardization (ISO). The MPEG SAOC has ability to reproduce multichannel audio at the decoder side. In this paper, performance of the MPEG SAOC on multichannel audio reproduction is analyzed and compared to MPEG Surround (MPS). The results show both MPEG SAOC and MPS have Objective Difference Grade (ODG) at impeceptible level. However, the MPEG SAOC encoder can only supports one multichannel object audio input.
\end{abstract}

Keywords :Spatial Audio Object Coding, Object-based Audio, and Multichannel Audio

Copyright $\odot 2017$ JNTE. All rights reserved

\section{PENDAhUluan}

Teknologi informasi dan multimedia berkembang pesat belakangan ini, salah satunya televisi digital. Televisi digital masa depan dilengkapi dengan video dengan resolusi $7680 \times 4320$ piksel sehingga menghasilkan detail gambar yang baik [1]-[3]. Video berkualitas tinggi juga didukung oleh audio multikanal untuk menghasilkan audio tiga dimensi (3D Audio) [4]-[10]. Selain itu, televisi masa depan juga dilengkapi dengan audio berbasis objek yang memungkinkan pengguna untuk mengatur volume (level) dari masing-masing objek audio [11]. Contohnya pada tayangan pertandingan sepak bola, dengan teknologi audio berbasis objek, pengguna dapat mengeraskan dan melemahkan level masing-masing objek audio seperti objek suporter, komentator, dan pemain.

Penggunaan teknologi audio pada televisi masa depan akan membutuhkan bandwidth yang lebih besar dibandingkan televisi konvensional. Seperti penggunaan audio multikanal 5.1 yang membutuhkan bitrate sebesar $320 \mathrm{kbps}$ dengan pengkode Advanced Audio Coding (AAC) [12][14], sedangkan teknologi sebelumnya yang menggunakan audio stereo hanya membutuhkan bitrate sebesar $128 \mathrm{kbps}$ dengan pengkode yang sama. Demikian juga dengan penggunaan teknologi audio berbasis objek, yang mana setiap objek audio ditransmisikan secara independen, sehingga bitrate akan semakin meningkat seiring dengan penambahan jumlah objek audio. Sehingga gabungan teknologi audio audio multikanal dan audio berbasis objek pada televisi masa depan akan membutuhkan bitrate yang sangat besar. Untuk mengatasi permasalahan tersebut, lahirnya spatial audio object coding (SAOC) yang merupakan gabungan dari spatial audio coding [15]-[17] dan audio object coding [18]-[21] sehingga memiliki kemampuan untuk mentransmisikan audio berbasis objek multikanal lebih efisien.

MPEG Spatial Audio Object Coding (SAOC) merupakan pengkode audio berbasis objek pertama yang telah distandarisasi oleh International Organization for Standardization (ISO) [22]-[27]. MPEG SAOC dirancang untuk dapat mengkodekan objek-objek audio lebih 
efisien. Selain itu, MPEG SAOC juga memiliki kemampuan backward compatibility, sehingga pengaplikasian MPEG SAOC tidak akan menimbulkan permasalahan kompatibilitas yang menyebabkan decoder lama tidak dapat digunakan. Decoder MPEG SAOC juga mendukung reproduksi audio mono, stereo, binaural, dan multikanal, sehingga memberikan fleksibilitas pada sisi penerima.

Untuk reproduksi audio multikanal, MPEG SAOC menggunakan rendering matrix sebagai parameter untuk mengkonversi objek audio menjadi audio multikanal. Rendering matrix berisi infomasi level dan posisi virtual (spatial parameter) dari masing-masing objek. Adapun kemampuan rendering matrix untuk reproduksi audio multikanal pada MPEG SAOC belum sepenuhnya diketahui. Atas dasar itulah, pada paper ini akan dibahas kemampuan reproduksi audio multikanal MPEG SAOC beserta kelebihan dan kekurangannya.

\section{SPATIAL AUDIO OBJECT CODING}

Spatial Audio Object Coding (SAOC) dikembangkan dari prinsip kerja Spatial Audio Coding (SAC). Gambar 1a menunjukkan arsitektur SAC, yang mana pada sisi encoder SAC audio multikanal di-downmix menjadi audio mono atau stereo. SAC encoder juga mentransmisikan spatial parameter yang menunjukkan karakteristik hubungan antar kanal. Selanjutnya pada sisi decoder, audio downmix dikonversi kembali menjadi audio multikanal berdasarkan spatial parameter-nya. Metode yang digunakan oleh SAC ini dapat menghemat penggunaan bandwidth karena audio yang ditransmisikan hanya berupa audio mono atau stereo saja.

Metode yang digunakan pada SAC diadopsi oleh SAOC, sehingga SAOC juga memiliki kemampuan mentransimisikan objek audio lebih efisien. Encoder SAOC men-downmix objek audio menjadi audio mono dan stereo seperti yang ditunjukkan pada Gambar 1b. Selanjutnya, agar objek-objek audio dapat dipisahkan kembali pada sisi decoder, object parameter juga ditransmisikan ke sisi decoder SAOC. Kemudian, objek-objek audio yang telah dipisahkan oleh object decoder diumpankan ke renderer untuk dikonversi menjadi kanal audio keluaran Konversi objek audio menjadi kanal audio ini, diatur berdasarkan rendering matrix.
Rendering matrix pada SAOC merupakan representasi dari level (volume) dan posisi virtual dari masing-masing objek audio.

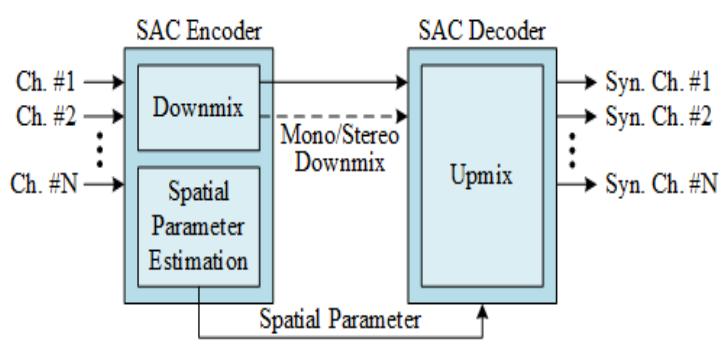

(a)

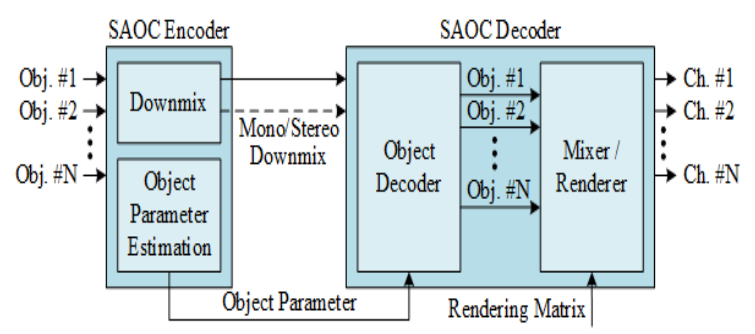

(b)

Gambar 1. Arsitektur (a) Spatial Audio Coding (b) Spatial Audio Object Coding

\section{MPEG SPATIAL AUDIO OBJECT CODING (MPEG SAOC)}

MPEG Spatial Audio Object Coding merupakan standar pengkodean audio yang dikeluarkan oleh ISO/MPEG Audio Standarization Group yang memiliki kemampuan untuk mengodekan audio berbasis objek [22]-[27]. Gambar 2 menunjukkan arsitektur encoder dan decoder MPEG SAOC. Pada sisi encoder, MPEG SAOC men-downmix objek audio masukan menjadi audio mono atau stereo. Objek audio masukan pada MPEG SAOC encoder dapat berupa audio mono ataupun stereo. Adapun jumlah objek maksimal yang mampu ditransmisikan oleh MPEG SAOC adalah 32 objek. Pada sisi decoder, berbeda dengan spatial audio object coding pada umumnya, MPEG SAOC menggunakan sistem dengan object decoder dan renderer yang terintegrasi. Dengan demikian MPEG SAOC tidak lagi mengurai objek-objek audio terlebih dahulu, melainkan langsung memodifikasi sinyal downmix dan me-render-nya menjadi audio berbasis kanal.

Terdapat dua tipe pendekode pada MPEG SAOC yaitu MPEG SAOC decoder dan MPEG 
SAOC transcoder. SAOC decoder digunakan untuk reproduksi audio mono dan stereo, sedangkan SAOC transcoder digunakan untuk reproduksi audio multikanal. Karena Paper ini hanya mengulas kemampuan reproduksi multikanal, sehingga hanya ditampilkan SAOC transcoder saja.

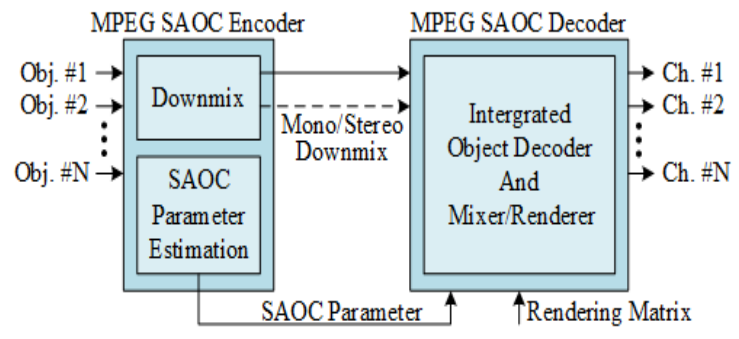

Gambar 2. Arsitektur MPEG SAOC

\subsection{MPEG SAOC Encoder}

Encoder MPEG SAOC memiliki 2 fungsi yaitu men-downmix objek-objek audio dan mengekstrak object parameter (SAOC Parameter). Sinyal downmix pada SAOC didefinisikan sebagai hasil perkalian downmix matrix $(D)$ dan objek audio $(S)$ [22].

$$
X=D S
$$

Downmix matrix berisi gain factor dari masing-masing objek audio yang nilainya ditentukan pada sisi encoder untuk mendapatkan audio downmix yang enak terdengar

MPEG SAOC memiliki beberapa object parameter yang dianalisis berdasarkan masukan objek audio. Jika $s_{i}^{n, k}$, merupakan objek audio ke- $i$ pada sampel ke- $n$ dan hybridband $k$, maka object parameter-nya adalah sebagai berikut [22]:

1. $n r g_{i, j}^{l, m}$ merupakan penjumlahan energi dari objek $i$ dan objek $j$ untuk timeslot/frame ke- $l$ dan processing/parameter band $m$.

$$
n r g_{i, j}^{l, m}=\frac{\sum_{n \in l} \sum_{k \in m} s_{i}^{n, k}\left(s_{j}^{n, k}\right)^{*}}{\sum_{n \in l} \sum_{k \in m} 1}+\varepsilon
$$

2. Absolute Object eNeRGy (NRG) merupakan energi dari objek audio yang memiliki energi tertinggi.

$$
N R G^{l, m}=\max _{i}\left(n r g_{i, i}^{l, m}\right)
$$

3. Object Level Difference (OLD) merupakan rasio perbandingan energi antara objek $i$ terhadap objek dengan energi tertinggi.

$$
O L D_{i}^{l, m}=\frac{n r g_{i, i}^{l, m}}{N R G^{l, m}}
$$

4. Inter Object Correlation (IOC) merupakan ukuran kemiripan atau korelasi antara objek audio $i$ dan objek audio $j$

$$
I O C_{i, j}^{l, m}=\operatorname{Re}\left\{\frac{n r g_{i, j}^{l, m}}{\sqrt{n r g_{i, i}^{l, m} n r g_{j, j}^{l, m}}}\right\}
$$

\subsection{MPEG SAOC Transcoder}

MPEG SAOC Trancoder merupakan pendekode MPEG SAOC yang digunakan untuk reproduksi audio multikanal. Dalam me-render objek-objek audio menjadi audio multikanal, SAOC transcoder melibatkan decoder MPEG Surround (MPS). Seperti yang ditunjukkan pada Gambar 3.

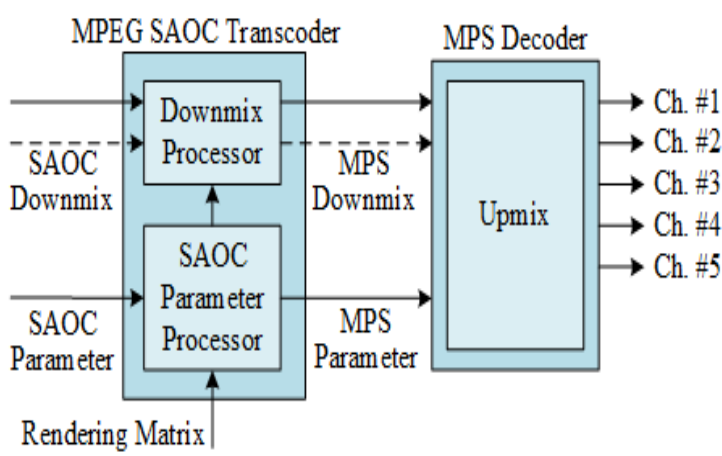

Gambar 3. Arsitektur MPEG SAOC Transcoder

SAOC Transcoder terdiri atas dua bagian yaitu downmix preprocessor yang berfungsi memodifikasi sinyal downmix dan SAOC parameter processor yang berfungsi mensintesis MPS parameter berdasarkan SAOC parameter dan rendering matrix. Sinyal downmix yang dimodifikasi oleh downmix preprocessor berupa audio yang di atenuasi atau amplifikasi objekobjeknya berdasarkan rendering matrix. Dengan demikian, MPS Decoder hanya me-render atau mengkonversi audio downmix menjadi audio multikanal berdasarkan MPS parameter. Adapun proses modifikasi dan sintesis MPS parameter pada SAOC transcoder dapat dilihat pada [22], dan proses upmix pada MPS decoder dapat dilihat pada [17]. 


\subsection{Multichannel Background Object (MBO)}

MPEG SAOC encoder hanya dapat menerima masukan objek audio mono dan stereo. Fitur Multichannel Background Object berfungsi agar MPEG SAOC encoder memiliki kemampuan untuk menerima masukan objek audio multikanal dengan memanfaatkan MPS encoder seperti yang ditunjukkan pada Gambar 4. Dengan menggunakan fitur MBO, objek audio multikanal di-downmix menggunakan MPS encoder untuk menghasilkan audio downmix mono atau stereo. Karena telah berupa objek audio mono atau stereo, audio downmix dapat menjadi masukan MPEG SAOC encoder. Agar objek audio tersebut dapat dikonversi kembali menjadi audio multikanal, MPS parameter yang dihasilkan MPS encoder ditransmisikan ke sisi penerima. Penggunaan fitur MBO hanya mendukung masukan satu buah objek audio multikanal saja.

\section{PENGUJIAN KEMAMPUAN RENDERING SYSTEM MULTIKANAL MPEG SAOC}

Rendering System MPEG SAOC memiliki kemampuan untuk reproduksi audio multikanal menggunakan rendering matrix sebagai spatial parameter-nya. Pada paper ini, dilakukan pengujian untuk mengetahui kemampuan rendering matrix untuk reproduksi audio multikanal. Sebanyak 5 buah audio yang akan digunakan pada pengujian ini ditunjukkan pada Tabel 1. Penggunaan rendering matrix sebagai spatial parameter akan dibandingkan dengan MPS parameter yang digunakan pada MPEG Surround (MPS) yang telah teruji kemampuannya dalam reproduksi audio multikanal.

Tabel 1. Audio yang Diujikan

\begin{tabular}{|c|c|}
\hline Audio & Deskripsi \\
\hline Tepuk Tangan & Audio orang bertepuk tangan \\
\hline Tertawa & Audio beberapa orang tertawa \\
\hline Band Akustik & Bunyi gendang diiringi suara pria \\
\hline Berita & Pria dan wanita membaca berita \\
\hline Musik Klasik & Musik klasik dengan vokal wanita \\
\hline
\end{tabular}

Adapun diagram blok pengujian kinerja rendering matrix dan MPS parameter dalam reproduksi audio multikanal ditunjukkan pada Gambar 5. Kemampuan rendering matrix dan MPS parameter dalam reproduksi audio multikanal akan diuji menggunakan parameter Signal to Noise Ratio (SNR)[28]. Selain itu, rendering matrix dan MPS parameter juga diuji menggunakan Perceptual Evaluation of Audio Quality (PEAQ) untuk mengetahui kualitas audio yang dihasilkan secara perceptual [29]-[31]. Dengan menggunakan PEAQ, kualitas audio dinilai dalam skala Objective Difference Grade (ODG) yang menunjukkan skala gangguan atau penurunan kualitas audio yang ditunjukkan pada Tabel 2 .

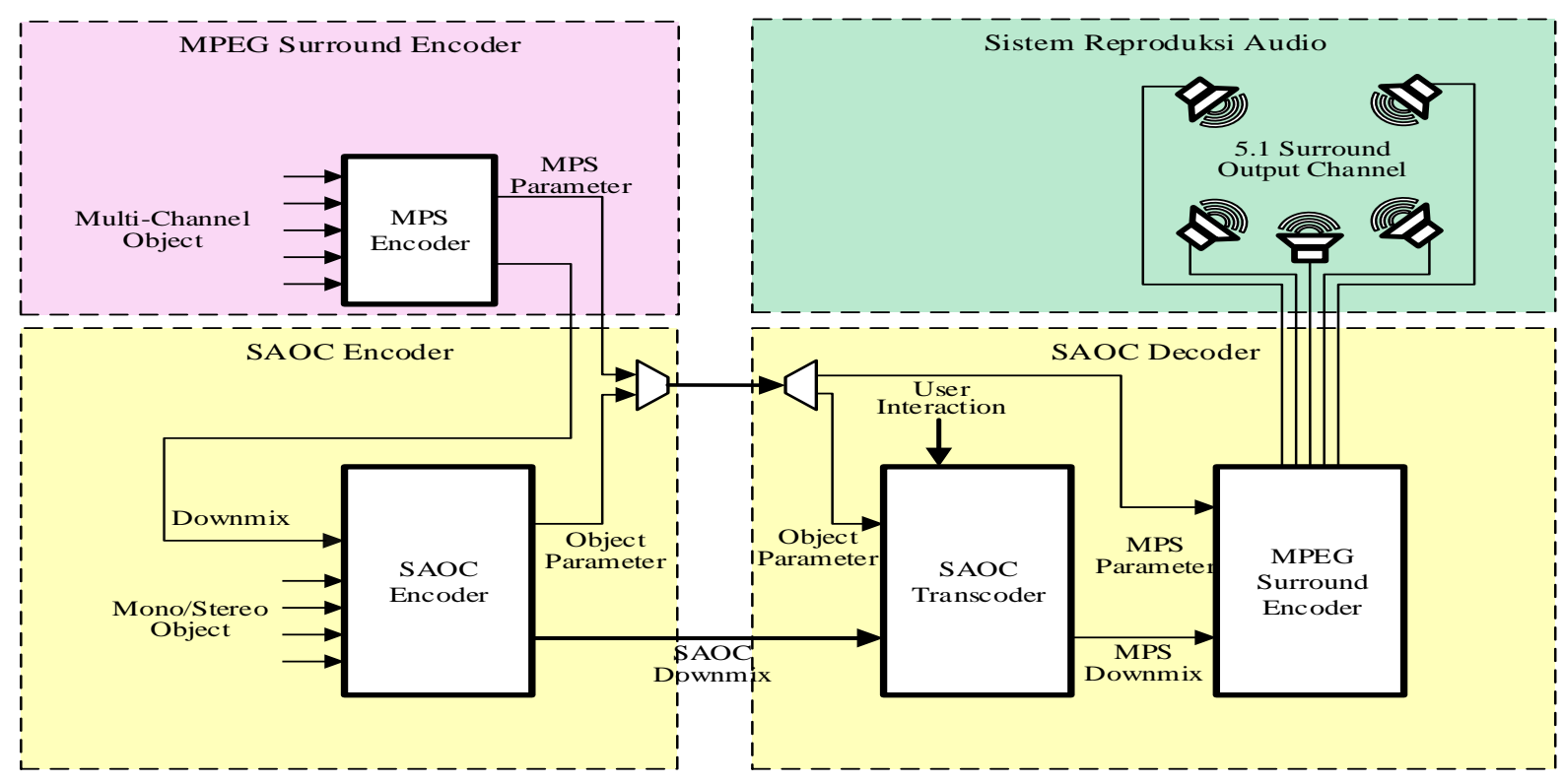

Gambar 4. MPEG SAOC dengan Multichannel Background Object 


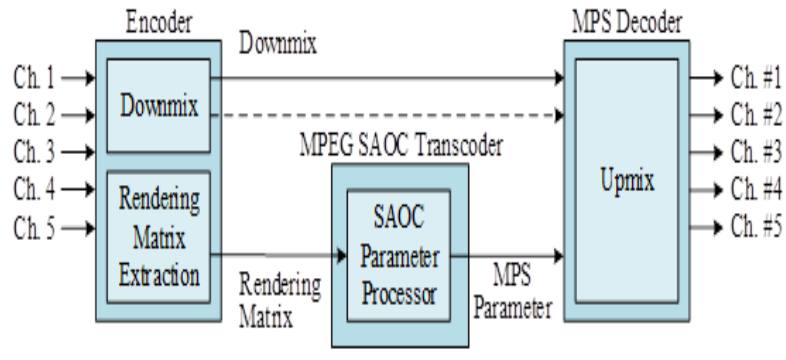

(a)

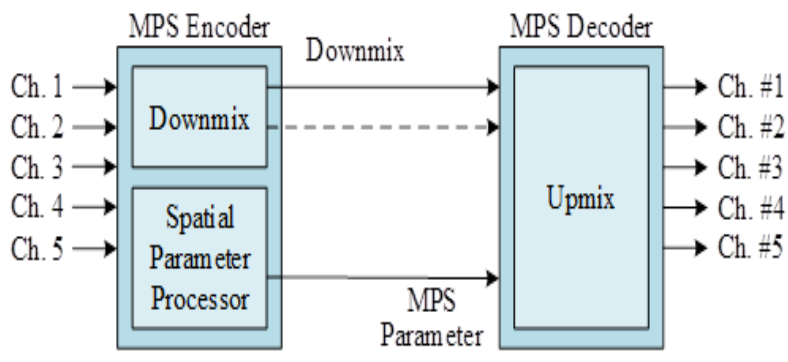

(b)

Gambar 5. Diagram Blok Pengujian (a) Rendering Matrix dan (b) MPS Parameter sebagai Spatial Parameter

Tabel 2. Deskripsi

Kualitas

Audio berdasarkan Nilai ODG

\begin{tabular}{|c|c|}
\hline Nilai ODG & Deskripsi \\
\hline 0 & Tidak terdengar gangguan, imerceptible \\
\hline-1 & $\begin{array}{r}\text { Terdengar gangguan namun tidak } \\
\text { mengganggu }\end{array}$ \\
\hline-2 & $\begin{array}{c}\text { Terdengar gangguan dan } \\
\text { sedikit menggangu }\end{array}$ \\
\hline-3 & terdengar gangguan dan mengganggu \\
\hline-4 & $\begin{array}{c}\text { terdengar gangguan yang } \\
\text { sangat mengganggu }\end{array}$ \\
\hline
\end{tabular}

\section{ANALISIS KINERJA}

Rendering system pada decoder MPEG SAOC menggunakan rendering matrix sebagai spatial parameter yang menunjukkan posisi virtual dari objek audio. Berdasarkan signal-tonoise ratio (SNR) pada Tabel 3, penggunaan rendering matrix sebagai spatial parameter memiliki SNR yang lebih tinggi dibandingkan penggunaan MPS parameter yang digunakan pada MPEG Surround. Peningkatan nilai SNR ini menunjukkan, penggunaan rendering matrix memiliki kemampuan rekonstruksi sinyal audio multikanal yang lebih baik dibandingkan MPS parameter. Selain itu, berdasarkan nilai objective difference Grande (ODG), penggunaan rendering matrix dan MPS parameter memiliki kualitas audio yang sama, yaitu pada level imperceptible. Hal ini menunjukkan penggunaan rendering matrix sebagai spatial parameter menghasilkan kualitas audio multikanal yang baik, sama seperti MPS parameter yang telah teruji kemampuannya.

Tabel 3. SNR dan ODG hasil pengujian

\begin{tabular}{|c|c|c|c|c|}
\hline \multirow{2}{*}{ Audio } & \multicolumn{2}{|c|}{ Rendering Matrix } & \multicolumn{2}{c|}{ MPS Parameter } \\
\cline { 2 - 5 } & SNR & ODG & SNR & ODG \\
\hline Tepuk Tangan & 32,47 & 0,107 & 21,86 & $-0,057$ \\
\hline Tertawa & 32,90 & 0,105 & 24,74 & 0,067 \\
\hline Band Akustik & 31,28 & $-0,027$ & 23,90 & $-0,138$ \\
\hline Berita & 31,29 & $-0,010$ & 24,75 & $-0,119$ \\
\hline Musik Klasik & 34,37 & 0,141 & 21,85 & $-0,146$ \\
\hline
\end{tabular}

MPEG SAOC juga mendukung objek audio multikanal sebagai masukan pada sisi encoder menggunakan fitur Multichannel Background Object (MBO). Namun, fitur ini hanya mendukung masukan satu objek audio multikanal saja, sehingga menimbulkan masalah saat MPEG SAOC digunakan untuk aplikasi lain seperti spatial karaoke (3D-Karaoke). Pada aplikasi spatial karaoke seluruh objek audio harus berupa audio multikanal untuk memberikan efek 3D. Dengan demikian MPEG SAOC masih memiliki kelemahan pada sisi encoder dalam reproduksi audio multikanal.

\section{KESIMPULAN}

Decoder MPEG SAOC memiliki kemampuan rendering system yang baik untuk reproduksi audio multikanal ditunjukkan dengan Objective Difference Grade (ODG) pada level imperceptible. Namun, encoder MPEG SAOC hanya mendukung masukan satu objek audio multikanal saja. Meningkatkan kemampuan encoder MPEG SAOC untuk dapat mendukung banyak masukan objek audio multikanal akan menjadi topik menarik untuk diteliti, sehingga kemampuan rendering system MPEG SAOC dapat digunakan secara optimal.

\section{DAFTAR PUSTAKA}

[1] T. Ito, "Future television - super hi-vision and beyond," in Proc. IEEE Asian Solid State Circuits Conference, 2010.

[2] Y. Shishikui, I. Kazuhiza, S. Sakaida, K. Kazui, and A. Nakagawa, "High 
Performance video-codec for Super HiVision," in Proceedings of the IEEE, 2013, pp. 130-139.

[3] E. Nakasu, "Super Hi-Vision on the horizon: A future TV system that conveys an enhanced sense of reality and presence," IEEE Consumer Electronics Magazine, pp. 36-42, 2012.

[4] "Multichannel Stereophonic Sound System with and without Accompanying Picture BS Series,'ITU-R BS.775-3, 2012.

[5] S. Kim, Y. Lee, and V. Pulkki, "New 10.2Channel Vertical Surround System (10.2VSS): Comparasion Study of Perceived Audio Quality in Various Multichannel Sound Systems with Height Loudspeakers." Presented at AES 129th AES Convention, San Fransisco, USA, 2010.

[6] K. Hamasaki, K. Hiyama, and R. Okumura, "The 22.2 multichannel sound system and its application," Presented at 118th AES Convention. Barcelona, Spain, pp. 1-11, 2005.

[7] K. Hamasaki, T. Nishiguchi, R. Okumura, and Y. Nakayama, "Wide Listening Area with Exceptional Spatial Sound Quality of a 22.2 Multichannel Sound System." Vienna, Austria, 2007.

[8] T. Sugimoto, Y. Nakayama, and S. Oode, "Bitrate of 22.2 Multichannel Sound Signal Meeting Broadcast Quality," in Proc. 137th AES Convention, 2014.

[9] T. Nishiguchi, T. Sugimoto, Y. Nakayama, and K. Hamasaki, "Production and Live Transmission of 22.2 Multichannel Sound with UltrahighDefinition TV," in Proc. 122nd AES Convention, 2013.

[10] K. Matsui and A. Ando, "Binaural Reproduction of 22.2 Multichannel Sound with Loudspeaker Array Frame," in Proc. 135th AES Convention, 2013.

[11] R. Bleidt, A. Borsum, H. Fuchs, and S. M. Weiss, "Object-Based Audio: Opportunities for Improved Listening Experience and Increased Listener Involvement," Motion Imaging Journal, SMPTE, vol. 124, no. 5, pp. 1-13, 2015.

[12] K. Brandenburg and M. Bosi, "ISO/IEC MPEG-2 Advanced Audio Coding: Review and Applications," AES 103rd
Convention. New York, USA, 1997.

[13] "Information Technology - Generic Coding of Moving Pictures and Associated audio Information, Part 7: Advanced Audio Coding," ISO/IEC 13818-7, 2006.

[14] M. Bosi, K. Brandenburg, S. Quackenbush, L. Fielder, K. Akagiri, H. Fuchs, M. Dietz, J. Herre, G. Davidson, and Y. Oikawa, "ISO/IEC MPEG-2 Advanced Audio Coding," J. Audio Eng. Soc., vol. 45, no. 10, pp. 789-814, 1997.

[15] J. Herre, J. Breebaart, C. Faller, S. Disch, K. Kjorling, E. Schuijers, J. Hilpert, and F. Myburg, "The Reference Model Architecture for MPEG Spatial Audio Coding." Presented at AES 118th AES Convention, Barcelona, Spain, 2005.

[16] I. Elfitri, "Spatial Audio Coding," TeknikA, vol. 1, no. 32, pp. 14-18, 2009.

[17] J. Breebaart, G. Hotho, J. Koppens, E. Schuijers, W. Oomen, and S. van de Par, "Background, concept, and architecture for the recent MPEG surround standard on multichannel audio compression," $J$. Audio Eng. Soc., vol. 55, no. 5, pp. 331351, 2007.

[18] M. Jia, Z. Yang, C. Bao, X. Zheng, and C. Ritz, "Encoding multiple audio objects using intra-object sparsity," IEEE Trans. Audio, Speech Lang. Process., vol. 23, no. 6, pp. 1082-1095, 2015.

[19] K.-L. Huang, T.-M. Chang, and P.-C. Chang, "An Object-Based Audio Rendering System using Spatial Parameters," in The 1st IEEE Global Conference on Consumer Electronics 2012, 2012, pp. 687-688.

[20] C. S. Cho, J. W. Kim, H. S. Shin, and B. H. Choi, "Implementation of an object audio system based on MPEG-4 audio lossless coding on DSP," IEEE Int. Symp. Broadband Multimed. Syst. Broadcast. 2010, BMSB 2010 - Final Program., pp. $1-5,2010$.

[21] S. Gorlow, E. A. P. Habets, and S. Marchand, "Multichannel object-based audio coding with controllable quality," in ICASSP, IEEE International Conference on Acoustics, Speech and Signal Processing - Proceedings, 2013, pp. 561565.

[22] "Spatial Audio Object Coding,"ISO/IEC 
23003-2, 2010.

[23] J. Engdegard, B. Resch, C. Falch, O. Hellmuth, J. Hilpert, A. Hoelzer, J. Breebaart, J. Koppens, E. Schuijers, and W. Oomen, "Spatial Audio Object Coding ( SAOC ) - The Upcoming MPEG Standard on Parametric Object Based Audio Coding," Presented at 124th AES Convention. Amsterdam, The Netherlands, 2008.

[24] J. Herre and S. Disch, "New Concepts in Parametric Coding of Spatial Audio: From SAC to SAOC," in IEEE International Conference on Multimedia and Expo, 2007.

[25] C. Falch, L. Terentiev, and J. Herre, "Spatial Audio Object Coding With Enhanced Audio Object Separation," in DAFx-10: proceedings of the 13th International Conference on Digital Audio Effects DAF, 2010.

[26] J. Park, J. Hong, K. Kim, and M. Hahn, "Harmonic elimination structures for Karaoke Mode in Spatial Audio Object Coding Scheme," in IEEE International Conference on Consumer Electronics (ICCE) Harmonic, 2011, pp. 813-814.

[27] O. Hellmuth, H. Purnhagen, J. Koppens, J. Herre, J. Engdegård, J. Hilpert, L. Villemoes, L. Terentiv, C. Falch, A. Hölzer, M. L. Valero, B. Resch, H. Mundt, and H. O. Oh, "MPEG Spatial Audio Object Coding-The ISO/MPEG Standard for Efficient Coding of Interactive Audio Scenes," J. Audio Eng. Soc., vol. 60, no. 9, pp. 655-673, 2012.

[28] Aude, Arlo J. 1998. Audio Quality Measurement Primer. AN9789

[29] ITU-R BS.1387-1: "Method for Objective Measurements of Perceived Audio
Quality", 2001.

[30] Liebetrau, J., Sporer, T., Kampf, S., Schneider, S.: "Standarization of PEAQMC: Extension of ITU-R BS.1387 to Multichannel Audio". Presented at AES 40th Int. Conf, Spatial Audio: Sense the Sound of Space, Tokyo, Japan, October 2010.

[31] Kabal, P.: "An examination and interpretation of ITU-R BS.1387: perceptual evaluation of audio quality", Telecommunication and Signal Processing Laboratory, Department of Electrical and Computer Engineering, McGill University.

\section{Biodata Penulis}

Amirul Luthfi, lahir pada tanggal 5 Desember 1993 di Kerinci. Penulis merupakan alumni Jurusan Teknik Elektro, Fakultas Teknik, Universitas Andalas dan sekarang sedang melanjutkan studi pada Program Studi S2 Teknik Elektro Universitas Andalas.

Ikhwana Elfitri, menyelesaikan pendidikan Sarjana dan Magister pada bidang Teknik Telekomunikasi di Institut Teknologi Bandung (ITB) dan Doktoral pada Department of Electronics, University of Surrey, Inggris. Saat ini Dr. Elfitri bekerja sebagai dosen dengan jabatan akademik Lektor Kepala pada Jurusan Teknik Elektro, Universitas Andalas. Sejak tahun 2011, ia telah secara aktif menjadi reviewer pada beberapa jurnal ilmiah termasuk IEEE Transaction on Multimedia dan IET Signal Processing. Dr. Elfitri adalah member the Institute of Electrical and Electronics Engineer (IEEE) sejak tahun 2012 dan Audio Engineering Society (AES) mulai tahun 2015. 